\title{
Anatomic Stage IIIC Breast Cancer AJCC v8
}

National Cancer Institute

\section{Source}

National Cancer Institute. Anatomic Stage IIIC Breast Cancer A/CC v8. NCI Thesaurus.

Code C139544.

Stage IIIC includes: Any T, N3, M0. N3: T umor with metastases in 10 or more axillary lymph nodes; or in infraclavicular (level III axillary) lymph nodes; or positive ipsilateral internal mammary lymph nodes by imaging in the presence of one or more positive level I, II axillary lymph nodes; or in more than three axillary lymph nodes and micrometastases or macrometastases by sentinel lymph node biopsy in clinically negative ipsilateral internal mammary lymph nodes; or in ipsilateral supraclavicular lymph nodes. M0: No clinical or radiographic evidence of distant metastases. Imag ing studies are not required to assign the M0 category. (AJCC 8th ed.) 